\title{
CORRECTIONS
}

\section{Pension funds: tobacco investment up in smoke}

In the fourth paragraph of this feature (BMJ 2016;352:11491, doi:10.1136/bmj.i1491), the fund that Health Super merged with was First State Super not First Union, and it did not lose investments by divesting from tobacco companies but reallocated them. In addition, in the penultimate paragraph, Bronwyn King said that engaging with the tobacco industry is futile, not "fatal" as was published. 